\title{
Simulation on launching exhaust field of underwater missile during vertical hot launching
}

\author{
Ming Yang ${ }^{1, a}$, HanPing Wang ${ }^{2, b}$ and ShiPing Zhao ${ }^{3, c}$ \\ ${ }^{1}$ Beijing Institute of Technology, BeiJing \\ ${ }^{2}$ Beijing Institute of Technology, BeiJing \\ ${ }^{3}$ Zhengzhou Institute of Electrical and Mechanical Services, ZhengZhou \\ ayangming19850420@163.com
}

Keywords: submarine-launched launching exhaust field Injection

\begin{abstract}
The model on launching exhaust field of underwater missile was based on viscous non-stationary compressible phase flow theory. In this paper, a reasonable modeling approach of launching exhaust field was obtained by analyzing whether to consider the vaporization effect. The article also analyzed the pros and cons of water injection program. Analysis showed that the launch barrel temperature decreased significantly with injection. On the other hand, poor exhaust problems might arise with injection, so injection quantity must be controlled. This article provides guidance for the scheme of launch.
\end{abstract}

\section{Launch modes of submarine-launched missiles}

In modern naval warfare, submarine-launched missiles have long range, good hit rate and hidden features. For forty years, the world's naval power attaches great importance to the Submarine missile launch technology.

Two launching modes classification based on the position relationship between the launcher and launch platform. One is the use of horizontal torpedo launchers. The other is the use of specialized vertical launcher.

Another classification method based on whether to use the carrier. One is the missile launch without carrier. Submarine ballistic missile with the large size., and its most of the trip outside the atmosphere with low aerodynamic characteristics. Therefore, ballistic missile launch without carrier. The other is underwater-launched missiles with carrier. The launch vehicle is equipped with missiles container. Its has a good hydrodynamic performance. Using the Launch program can reduce the missile's design requirements, and can design the missile shape with the aerodynamic requirements. Whether to use the launch vehicle is not essentially different, viewed from the launch dynamics point.

There is also a classification based on sources of Launch Power. One is cold launch with the Launch Power coming from launcher. The other is hot launch that with the Launch Power coming from rocket engine. With simple design., low noise, good concealing are significant advantages of cold launch;The disadvantage is that the anti-interference ability is weak, with large dispersion. Hot launch ensure that the missile trajectory is controllable, and ensure water ballistic in good condition.

In order to improve the probability of survival of the submarine, the requirements of submarine-launched depth to further increase. Cold launch will lead to the design difficulties of the launcher, and its water ballistic characteristics are difficult to guarantee. In order to minimize the travel of the missile in the water, strengthen the missile motion control, and ensure the missile a good aerodynamic shape, the use of vertical hot launch with launch vehicle is an inevitable choice.

Thermal emission has its own characteristics. They are high launched back pressure, gas exhaust is restricted and missiles need to pass through two very different media. How to implement the gas exhaust without structural damage or interfere with missile movement is a main consideration of thermal launched program.

As the complexity of the underwater launch, experiment design difficult and expensive. In order to effectively assess and reduce the blindness of the trial, numerical simulation is an inevitable 
choice.

\section{Modeling}

\section{Basic Hypothesis.}

(1)The flow field is axisymmetric structure.

(2)Flow field of gas is only a single gas.

(3)Does not consider the effect of the thermal conductivity between the flow field and the launcher.

(4)Assume that the gas burner full, without regard to the gas resurgence effect.

\section{The choice of the numerical model.}

The RNG model is commonly used in the calculation of the flow field, which applies to fully developed turbulence. The near-wall flow field calculations using the wall function method to be dealt with.

The effect of gas-liquid two-phase flow using the mixture model to display. Mixture model is characterized by two-phase coupling effects.

The analysis of the movement of the submarine-launched missiles must consider the problem of cavitation. Cavitation is the vaporization phenomenon of fluid flow under a certain pressure and temperature. Bubbles generate and collapse will affect the movement of the missile. But consider the effect of cavitation may cause numerical problems. For this analysis, estimates the cavitation number between 0.86 and 1.5. This indicates a low probability of occurrence of cavitation. Part of the missile in the gas parcels, the missile body and the water contact is not sufficient, which further reduce the possibility of the occurrence of cavitation during launch. Create a model does not consider gas effect to verify the possibility of cavitation occurring. No cavitation in the process of the missile launch by the simulation. Therefore, in the model does not consider the impact of cavitation.

High-temperature gas, the water is boiling occurs, to produce steam. However, considering the seawater boiling in the model, which worth discussing the impact on the accuracy of simulation models.

\section{Boundary and Initial conditions.}

The model consists mainly of three types of boundary conditions. They are wall boundary conditions, pressure inlet conditions, and pressure out conditions which defined by the static pressure formula.

Assumed internal and external pressures in equilibrium in the initial moment. Engine total temperature and total pressure linear growth to the actual working conditions in the $0.01 \mathrm{~s} \mathrm{time.}$

\section{Analysis of results}

\section{The impact of the vaporization effect.}

Whether to consider the vaporization effect, the flow field calculation results are in agreement, the difference is mainly reflected in the gas distribution. Without considering the vaporization of the missile speed is $31.36 \mathrm{~m} / \mathrm{s}$, considering the vaporization of the missile speed is $31.94 \mathrm{~m} / \mathrm{s}$. The results indicate that the dynamic characteristics are similar by whether to consider the vaporization effect.

Figure 2.1.1- Speed of cloud pictures;

Figure 2.1.2- Temperature cloud pictures

Figure 2.1.3- Gas fraction without vaporization

Figure 2.1.4- Gas fraction cloud pictures with vaporization

Figure 2.1.5- Steam phase fraction cloud pictures 


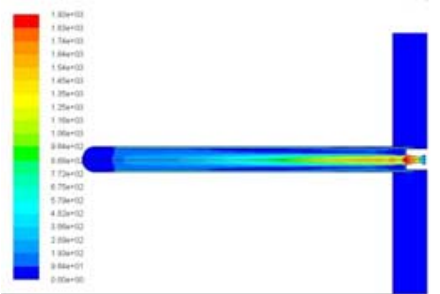

Figure 2.1.1

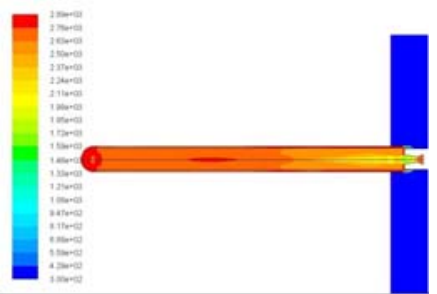

Figure 2.1.2

The maximum flow rate of the engine nozzle is $2000 \mathrm{~m} / \mathrm{s}$ or so, to achieve. During launch, the missiles and launchers in a high temperature above $2600 \mathrm{~K}$ by temperature cloud pictures. The high temperature may be damage the local structure of the missiles and launchers. This must be considered during the design stage.

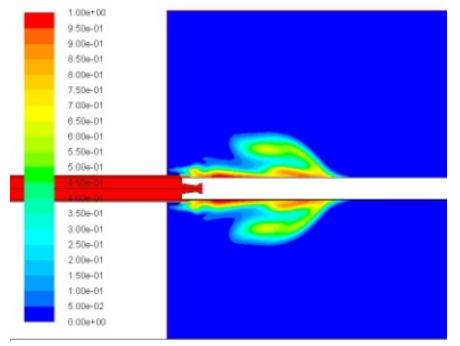

Figure 2.1.3

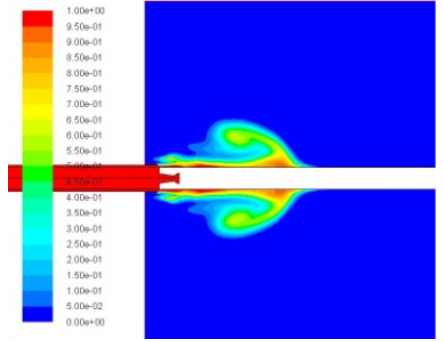

Figure 2.1.4

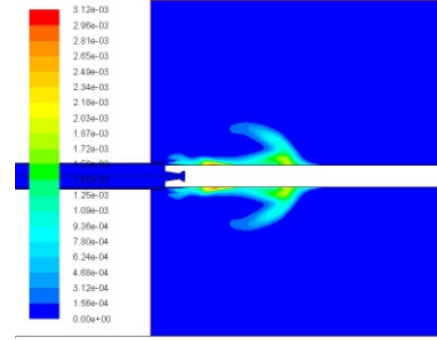

Figure2.1.5

The impact of water injection on the launch of the flow field.

The impact of water injection is mainly reflected in the temperature effect.

Temperature cloud pictures without injection:

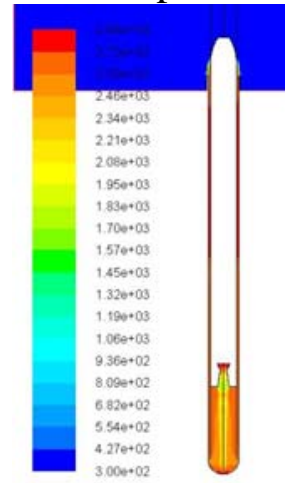

Time 1

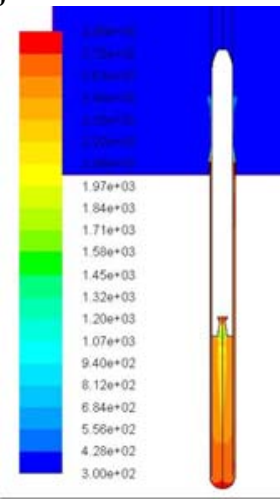

Time 2

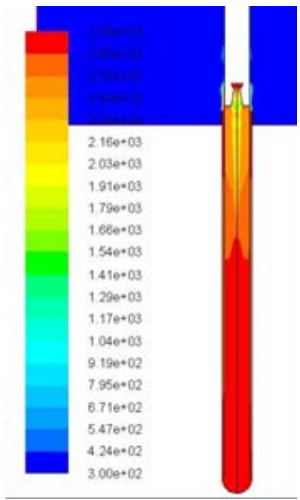

Time 3

Two water injection programs

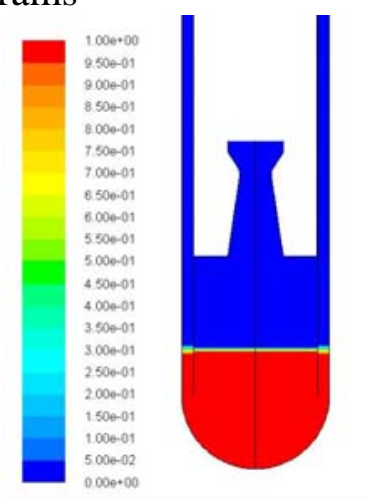

program 1

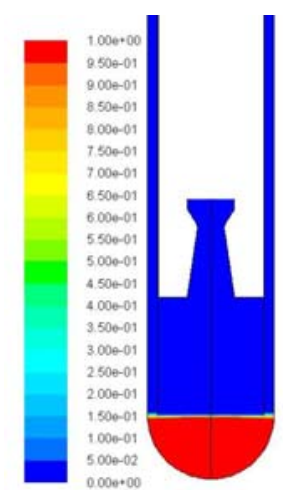

program 2

The first solution temperature cloud pictures: 


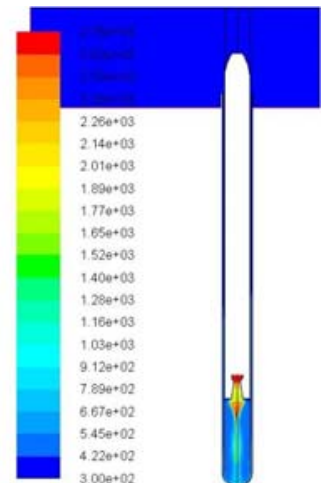

Time 1

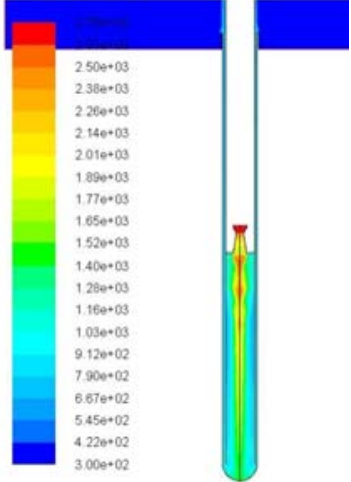

Time 2

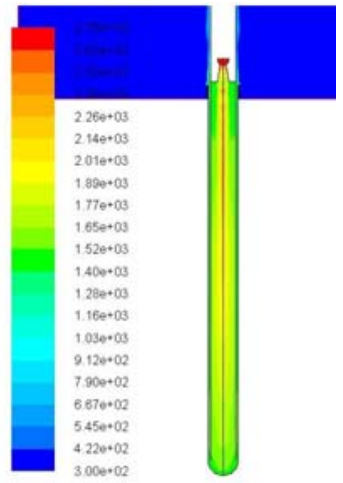

Time 3

The second solution temperature cloud pictures:

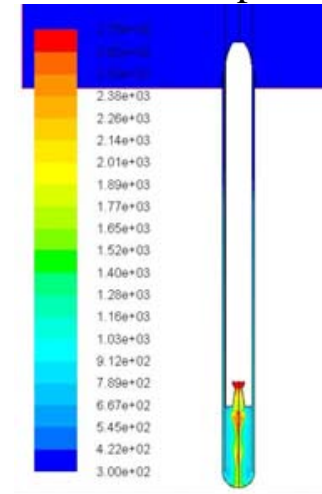

Time 1

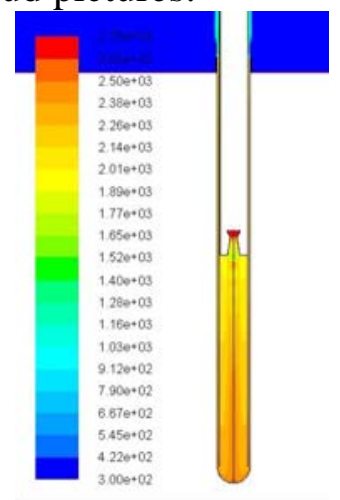

Time 2

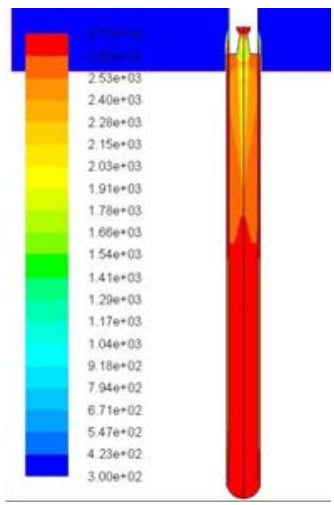

Time 3

Water injection programs significantly lower the temperature and the more water the more obvious effects. In addition, compared to no water injection, the missile speed is significantly different in water injection case. Missile speed of $37.78 \mathrm{~m} / \mathrm{s}$ in the first case, $35.68 \mathrm{~m} / \mathrm{s}$ in the second case. Two reasons led to the missile velocity increases. First the density of water is much larger than the gas, since a similar baffle, thereby increasing the thrust of the missile. Second, because water cannot be completely vaporized immediately, and part of the water enters the gap between the inside and outside cylinder, thus affecting the smooth drainage of gas, which caused the missile thrust increases.

\section{Conclusion}

(1)If the missile speed is low, it is reasonable to ignore the cavitation in a great depth case. This can simplify the model and enhance the stability of numerical calculation.

(2)Vaporization has little effect on the missile movement.

(3)The injection can significantly reduce the launch barrel temperature, can also increase the thrust of the missile launch. Too much water injection will bring Exhaust difficult, so the water injection rate should be controlled.

\section{References}

[1] Youji Zhang. The flight dynamics design. Aerospace Press. Beijing(1998).

[2] DeBin Fu. Application of Numerical in Aerospace Launching Technology National Defense Industry Press. Beijing(2011).

[3] HanPing Wang. Analysis of ejection after-effect for underwaterlaunched emulating missile. JOURNAL OF SHIP MECHANICS Vol. 14 (2010), p. 1122-1128

[4] ShiPing Zhao. Effects of lateral flow to the missile vertical launched from a submarine. JOURNAL OF SHIP MECHANICS Vol. 10 (2006), p. 33-37 